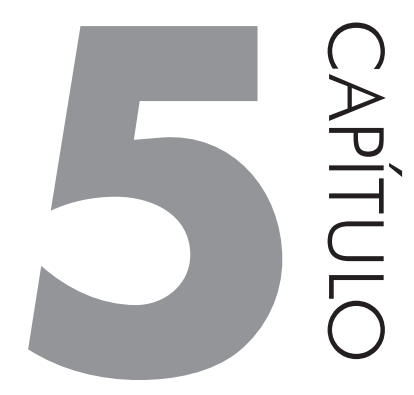

\title{
AVALIAÇÃO DE USABILIDADE DO NEWSGAME APRENDENDO JORNALISMO
}

\section{RICARDO LUIZ AOKI, PATRICIA JANTSCH FIUZA, ROBSON RODRIGUES LEMOS, VERA LUCIA SOMMER}

\section{INTRODUÇÃO}

O jornalismo talvez seja a área de conhecimento que mais sofre influência com a evolução tecnológica. Desde sua gênese arcaica com o primeiro grande fenômeno pré-jornalístico na Grécia antiga que foi a transposição de uma literatura oral para uma literatura escrita registrada em obras como Odisséia e Ilíada de Homero, a prática jornalística sempre é forçada a absorver os avanços da linguagem ou dos métodos tecnológicos que surgem em espaços de tempo cada vez menores.

Com a industrialização do papel durante o período do Renascentismo europeu foi possível acelerar a transposição do registro narrativo da oralidade para o papel e, posteriormente, com a invenção da prensa pelo alemão Johann Gutenberg (entre 1444 e 1456), criou-se o meio pelo qual a reprodução em massa dos registros escritos fosse difundida em larga escala.

As narrativas impressas desse período ainda não podiam ser chamadas de jornalismo e começaram realmente a ter importância no século XVII com o surgimento das gazetas na França. Nesse período surgiram os primeiros profissionais exclusivamente dedicados à redação das notícias. Sousa (2008, p. 80) afirma que o jornalismo noticioso é uma invenção europeia dos séculos XVI e XVII, 
com raízes remotas na antiguidade clássica e antecedentes imediatos na Idade Média e no Renascimento. Já no século XX o surgimento da televisão e a sua grande difusão após a II Guerra Mundial (Castells, 1999, p. 415) foi responsável pela primeira mudança significativa no processo jornalístico. Castells analisa claramente esse período ao afirmar que o surgimento da TV foi o marco do fim de um sistema de comunicação essencialmente dominado pela mente tipográfica.

Todas as revoluções tecnológicas da comunicação humana que surgiram desde a antiguidade serviram para moldar o jornalismo moderno baseado na pirâmide invertida e no interesse público. Entretanto, o surgimento dos computadores e em seguida da internet causaram mudanças estruturais na sociedade nunca antes vistas. As Tecnologias da Informação e Comunicação (TIC) colaboram para reestruturar o exercício da profissão, a produção de notícia e as relações entre fontes e empresas de comunicação (Bianco, 2004, p. 1). Pesquisadores como Michael Kunczik, Bill Kovack, Tom Rosentiel, Ignácio Ramonet e Dominique Wolton concordam que as TIC têm influência na organização da rotina de trabalho dos jornalistas. No entanto, eles duvidam que as tecnologias digitais tenham provocado mudanças profundas na concepção de jornalismo a ponto de alterar valores consagrados. (Bianco, 2004, p. 1).

Dessa forma é necessário pensar em como a revolução tecnológica e as TIC tem influenciado na produção de notícias e, principalmente, como a academia tem preparado os jovens jornalistas, da geração dos nativos digitais, para enfrentar o dia a dia das novas empresas de comunicação. Nativos digitais são justamente aquelas pessoas que nasceram após o surgimento da internet e que são habituados ao ambiente virtual (Prensky, 2012, p. 32). Para esses, uma das grandes estrelas da ciência da computação são os jogos digitais.

A Aprendizagem Baseada em Jogos Digitais (ABJD) tem se tornado um amplo campo de pesquisas. Para Prensky (2012, p. 22), “bem antes de os adolescentes de hoje terem netos, a aprendizagem baseada em jogos digitais - ou, precisamente, seus sucessores bem mais sofisticados - será considerada uma forma de aprender bastante normal". Esse efeito previsto por Prensky já pode ser notado em plataformas de aprendizagem digitais populares como Duolingo (Idiomas), Khan Academy (matemática) ou Codecademy (programação). Nesses ambientes os conceitos dos jogos são aplicados de forma tão sutil que, muitas vezes, o usuário não percebe que está aprendendo e jogando.

$\mathrm{O}$ aprendizado tradicional, onde o professor está sempre narrando o seu conhecimento para os estudantes, não está propriamente com seus dias contados. Ele está em transformação. Quando crianças pequenas entram na escola, elas são apresentadas formalmente para as narrativas tradicionais de aprendizado (Madej, 2007, p. 6, tradução nossa). Na ABJD a forma como o aprendizado é apresentado 
também se faz por um processo narrativo. Para Madej (2007, p. 6, tradução nossa) a "narrativa em jogos engloba uma natureza multimodal e interativa da mídia digital onde o resultado é diferente das formas narrativas tradicionais, mas compartilha características com experiência narrativa de impressão inicial”. Ou seja, o aprendiz percebe rapidamente quando uma mídia se trata de um suporte de aprendizado.

Esse artigo pretende entender o impacto de utilizar narrativas digitais aplicadas em Aprendizagem Baseada em Jogos Digitais no ambiente de ensino de um curso de jornalismo. Essa tarefa é um tanto quanto delicada tendo em vista que os videogames ainda são vistos de forma maniqueísta e com certo preconceito quando se pensa nos jogos digitais no ambiente educacional (Alves, 2008, p. 227). Ou seja, se faz necessário pensar em soluções inovadoras para a produção jornalística e, não apenas, também encontrar novas formas de ensino dos futuros jornalistas.

Portanto, houve um esforço dos pesquisadores em desenvolver uma ferramenta para o aprendizado da redação jornalística que fosse capaz de utilizar o conceito de Narrativa Digital em um ambiente de Aprendizado Baseado em Jogos Digitais. Assim sendo, criamos um newsgame com essa finalidade. Para Miguel Sicart (2008) os Newsgames são jogos sérios de computador projetados para ilustrar um aspecto concreto das notícias por meio de sua retórica processual, com o objetivo de participar no debate público. Entretanto, as pesquisas sobre Newsgames focam no público final da notícia e a proposta utilizada nessa pesquisa é criar um newsgame para o treinamento de jornalista. Utilizamos a Teoria Geral dos Newsgames para propor uma nova categoria educativa aos jogos jornalísticos. Ou seja, os Newsgames educativos. Surgiu assim o newsgame Educativo Aprendendo Jornalismo. O processo de desenvolvimento, testes e análise de usabilidade serão detalhados no decorrer desse trabalho.

\section{MÉTODOS}

Para o desenvolvimento do newsgame educativo se utilizou o Ciclo da Engenharia de Usabilidade como apresentado por Walter Cybis, Adriana Holtz Betiol e Richard Faust (2007, p. 104). A ideia central é que toda plataforma computacional deve primar o desenvolvimento de sua interface em um ciclo que tem o usuário como principal interlocutor.

O modelo de desenvolvimento de uma interface com o usuário deve permitir a realização de sucessivos ciclos de "análise $\rightarrow$ concepção $\rightarrow$ testes" (Cybis, Betiol $\&$ Faust, 2007, p. 104) permitindo assim que se gerem resultados que possibilitem novos ciclos até a concepção final do sistema.

Nessa fase inicial do projeto do newsgame para ensino de jornalismo foi descrita a concepção do que se pretendia obter com a criação desta aplicação 
educacional. Ainda com base na teoria dos autores mencionados foi necessário identificar a necessidade do projeto centrado no usuário, o qual representa um elemento importante no contexto do ciclo de engenharia de usabilidade (Cybis; Betiol; Faust, 2007, p. 105).

\subsection{Identificando a necessidade}

Desde o surgimento do primeiro jornal on-line do mundo, o San José Mercury News, em 1994, (Sousa, 2003) existe uma discussão acerca da linguagem jornalística nos meios digitais. Becker $(2013$, p. 27) relata que:

A dificuldade de se fazer jornalismo nesta era da convergência digital, entretanto, resulta de duas tradições: uma geral, característica da própria relação entre cultura e tecnologia, e outra mais diretamente ligada à formação dada pelo ensino superior aos profissionais das redações.

Pensando apenas na segunda dificuldade é preciso entender que o ser humano está habituado com um suporte tradicional que é a página. No jornalismo a página ainda é a principal forma de se pensar o formato da difusão de notícias. No Brasil o primeiro jornal a embarcar no mundo on-line foi o Jornal do Brasil (JB) em 1995. Entretanto, se analisarmos a página inicial do website do JB naquela época iremos notar uma grande semelhança com as páginas de jornais tradicionais e mesmo hoje, 22 anos após, a homepage do JB permanece lembrando a primeira página de um jornal impresso.

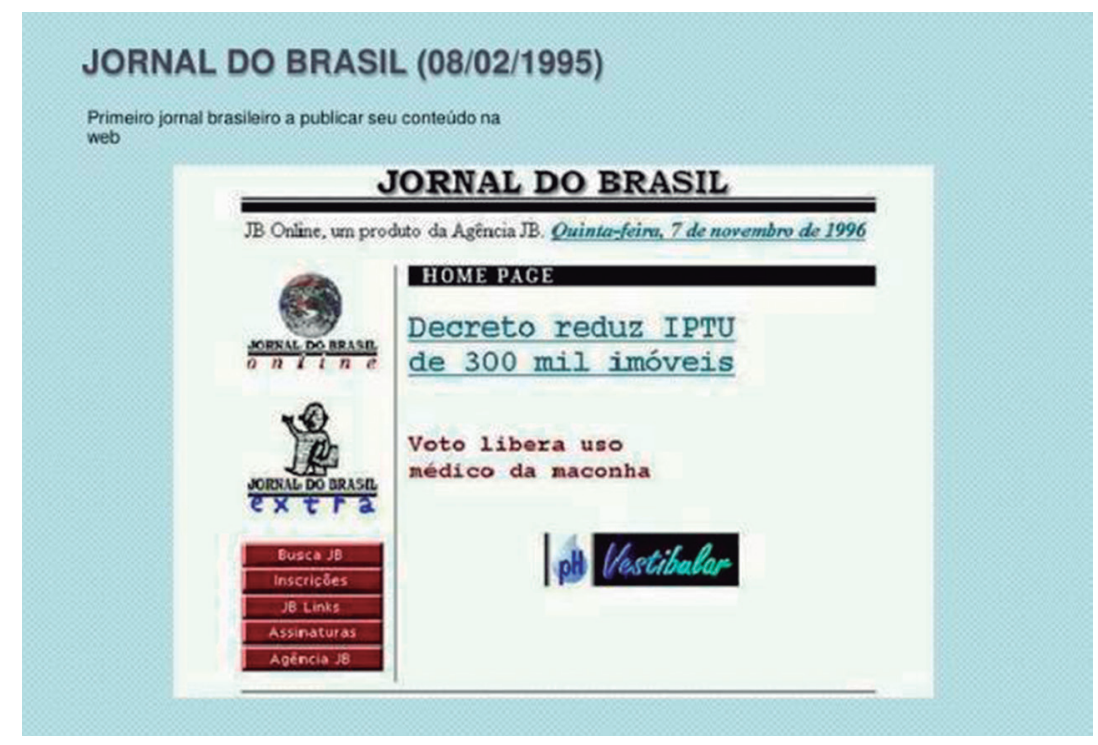

Figura 1 Capa JB online em 1995.

Fonte: Rodrigues, 2009. 

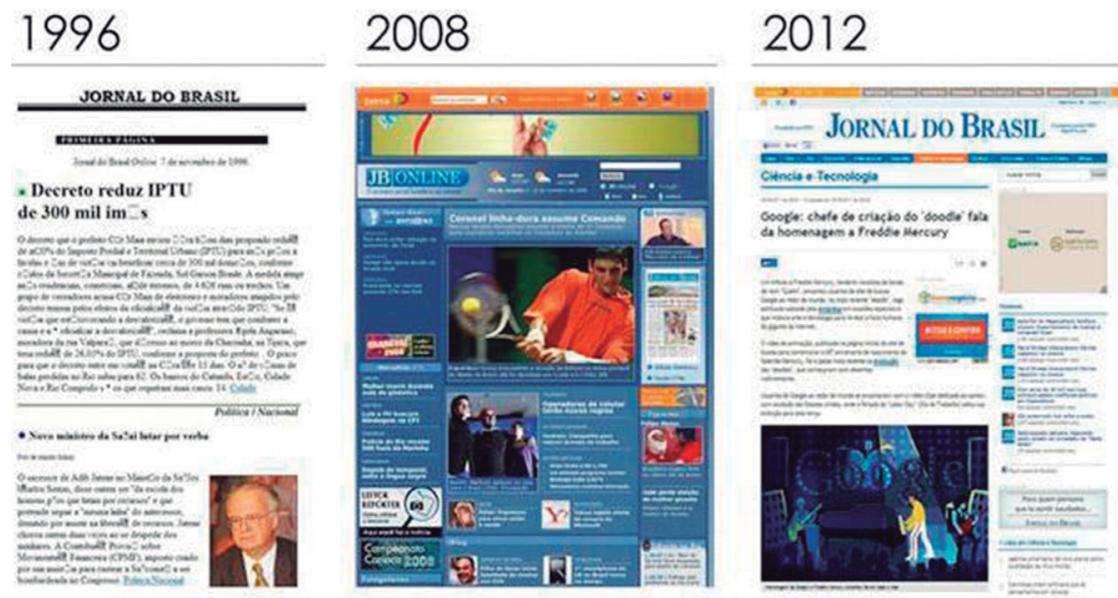

Figura 2 Evolução das Capas do JB.

Fonte: Site Rank Brasil - <http://bit.ly/1eeYPHb>.

Por muitos anos o ensino de redação jornalística foi feito com base no padrão de sucesso da indústria na era impressa e os atuais estudantes continuam sendo ensinados nesse modelo. Apesar de toda discussão acerca de novos métodos de ensino da prática jornalística no suporte digital, o texto ainda é focado na teoria da Pirâmide Invertida. Ou seja, o método de ensino é aquele onde o texto jornalístico deve iniciar do mais importante para o menos importante como representado na Figura 3.

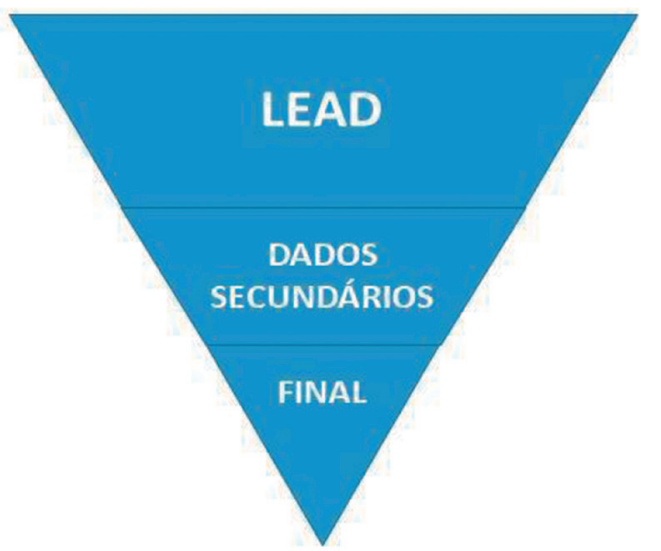

\section{+ importante}

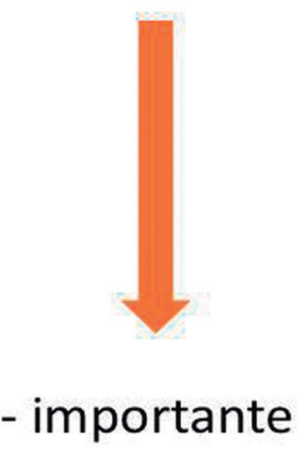

Figura 3 Esquema da Pirâmide Invertida.

Fonte: Elaborado pelo autor. Adaptado de Canavilhas (2006).

Entendendo que a Pirâmide Invertida continuará sendo o método consagrado da narrativa jornalística é necessário pensar em como adaptar o ensino da 
Redação Jornalística aos tempos de narrativas digitais não lineares e plataformas de informação gamificadas. Para Miguel Sicart, professor de Desenvolvimento de Games, do Instituto de Tecnologia de Massachusetts (MIT):

Os NewsGames são em sua essência 'jogos que utilizam o meio com a intenção de promover a participação no debate público'. Portanto, encarando o jornalismo a partir da cibercultura, é um equívoco pensar os games baseados em notícias de maneira compartimentada. (Seabra \& Santos, 2014)

Para Seabra e Santos (2014) os Newsgames ainda são um conceito em definição, tendo em vista que os pesquisadores da Teoria Geral dos Newsgames se focam nos impactos dos jogos de conteúdo jornalístico no público consumidor de notícias. Os autores do presente estudo de caso propõem uma nova categoria de Newsgames educacionais para o ensino e preparo dos futuros profissionais jornalistas.

Dessa forma, a proposta é a criação de um newsgame Educativo chamado Aprendendo Jornalismo que visa auxiliar os estudantes de jornalismo na tarefa de aprimorar o domínio da Redação Jornalística e suprir uma necessidade latente de preparar os futuros profissionais para a criação de textos em um ambiente de narrativas digitais.

\subsection{Participantes}

O estudo de caso do newsgame Aprendendo Jornalismo foi realizado com alunos de jornalismo do primeiro e oitavo períodos da Universidade do Vale do Itajaí (Univali) e com alunos do segundo período da Universidade do Sul de Santa Catarina (Unisul). No total participaram 32 alunos sendo 21 mulheres e 11 homens. A média de idade dos alunos é de 19 anos sendo que 14 declararam já trabalhar com jornalismo e 18 ainda não tem contato com o dia a dia da profissão. Metade dos alunos disseram que são intermediários no manuseio de jogos digitais educacionais. Três disseram ter nível avançado e 13 nunca tiveram contato. O teste foi realizado apenas com alunos possuidores de smartphones com sistema Android e os alunos com celulares iOS apenas observaram a atividade. Todas as professoras são jornalistas com ampla experiência no mercado sendo que uma tem titulação de doutorado e as outras duas são mestras.

\subsection{O newsgame Aprendendo Jornalismo}

O desenvolvimento do newsgame educativo foi baseado em três teorias: A primeira é a teoria das Narrativas Digitais, a segunda é a Aprendizagem Baseada 
em Jogos Digitais e finalmente a Teoria Geral dos Newsgames. O primeiro passo foi analisar ambientes de desenvolvimento onde fossem possíveis a criação de jogos educativos narrativos. Dessa forma, escolhemos o MIT App Inventor como ambiente de desenvolvimento.

O MIT App Inventor é um ambiente intuitivo de programação visual que permite a todos - mesmo crianças - criar aplicativos totalmente funcionais para smartphones e tablets (Hal Abelson, 2017). $\mathrm{Na}$ análise foi decidido pela sua utilização por se tratar de um ambiente de criação de aplicativos em blocos e considerou-se a vasta documentação em Língua Portuguesa e uma quantidade considerável de tutoriais para auxiliar o autor na construção do newsgame Aprendendo Jornalismo.

Segundo o site do projeto MIT App Inventor é possível ter um primeiro aplicativo simples e funcional em menos de 30 minutos (Hal Abelson, 2017). Os idealizadores também prometem a criação de aplicativos complexos em muito menos tempo do que os ambientes de programação tradicionais. Por se tratar de um ambiente de código aberto optamos por utilizar a versão Thunkable disponível em www.thunkable.com, que no momento do desenvolvimento era a plataforma mais atualizada do sistema.

\subsection{Narrativa do newsgame}

O primeiro passo para a criação do jogo digital foi a elaboração do roteiro da narrativa digital. Esse processo foi feito em papel e posteriormente transferido para um Power Point. Por se tratar de uma aplicação para ensino de jornalismo, o autor imaginou uma trilha narrativa com diversos personagens e caminhos possíveis. A trama central da narrativa é um caso fictício de tráfico de influências em uma prefeitura de uma cidade também fictícia. O que corrobora com a Teoria Geral dos Newsgames no sentido de fomentar que cada proposta de trama de newsgame deve usar uma temática social diferente: política, educação, cidade, esporte, ciência, tecnologia, entre outras. (Seabra \& Santos, 2014).

A ideia é que o estudante de jornalismo possa se deparar com situações cotidianas da cobertura jornalística, ter uma noção técnica sobre apuração de dados, entrevista de fontes e investigação e posteriormente a redação do título e lide (primeiro parágrafo) de uma matéria jornalística. Dessa forma, o aluno é introduzido ao jogo pelo editor do jornal que lhe fornece a pauta. Com os dados da pauta em mãos ele deve percorrer os locais indicados e entrevistar as fontes envolvidas. Ao final do percurso, que pode ter finais diferentes, ele recebe dicas e tem acesso às suas anotações para redigir o exercício proposto. 


\subsection{Personagens}

Quadro 1 Personagens do newsgame.

\begin{tabular}{|c|c|c|c|c|}
\hline & João & Juliana & Antonio & Vereador Luciano \\
\hline Editor & $\begin{array}{c}\text { Secretário do } \\
\text { prefeito da cidade } \\
\text { de Alto Feliz }\end{array}$ & $\begin{array}{c}\text { Chefe de Gabinete } \\
\text { do Prefeito } \\
\text { Empreiteira } \\
\text { de Obras }\end{array}$ & $\begin{array}{c}\text { Vereador e Irmão } \\
\text { de Antonio }\end{array}$ \\
\hline
\end{tabular}

Fonte: Elaborado pelos autores - Imagens: Licença CC site Pixabay.

\subsection{A trama aliada à interface}

A interface do jogo, nessa versão alfa, é bem simples. O jogo inicia com uma breve introdução onde se reproduziu uma ideia de primeira capa de jornal (Figura 4). Ao ser introduzido na narrativa o aluno receberá a pauta com o editor (Figura 5). Em seguida ele é conduzido para a entrevista com as fontes (Figura 6). A interação sempre se dá pelo toque na tela e o jogador sempre utiliza um botão na cor preta para seguir no jogo.

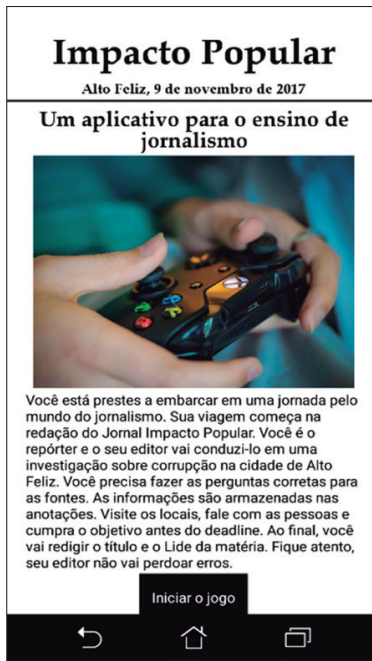

Figura 4 Introdução.
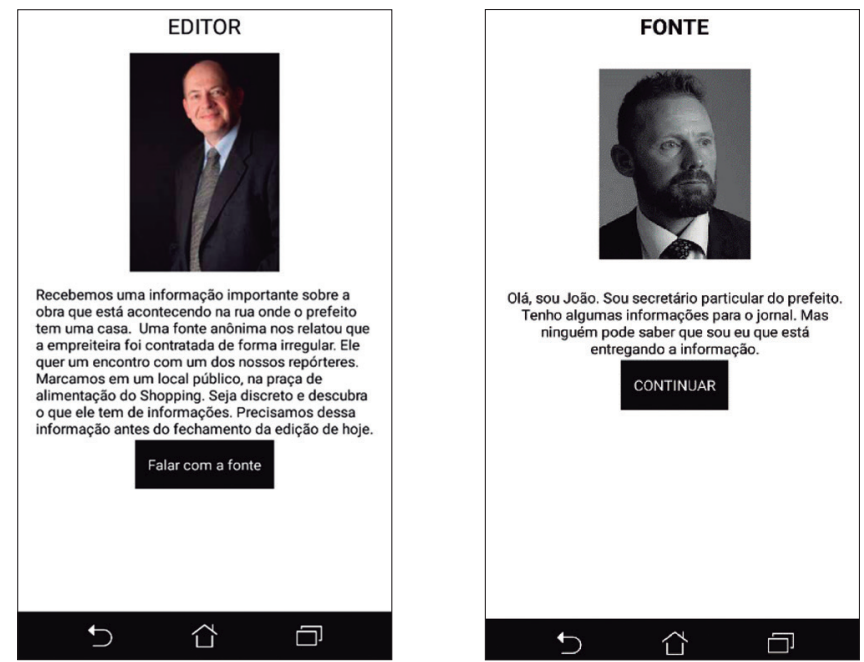

Figura 5 Editor entrega a pauta. Figura 6 Entrevista com a fonte. Imagens: Capturas de tela. Fotos: Licença CC Pixabay. 
A primeira interação com a fonte João (Figura 7) abre duas possibilidades de caminhos para o jogador que conduzem a finais diferentes (Figuras. 8 e 9). A lógica é que sempre surgirão duas perguntas que o repórter possa fazer para a fonte. Feita a pergunta, esta não retorna ao jogo.

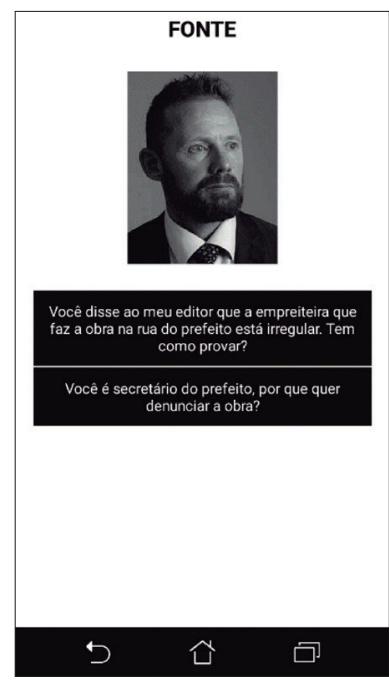

Figura 7 Primeira Interação.

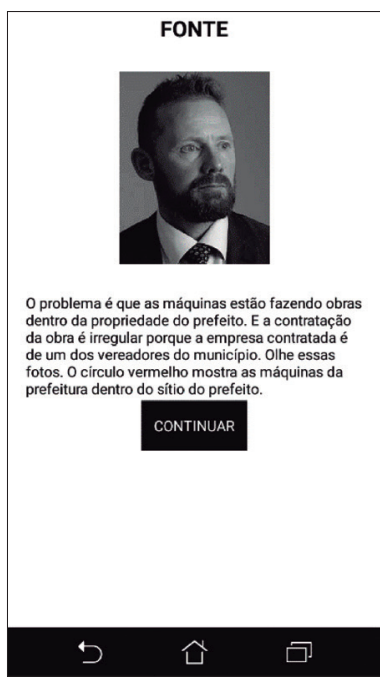

Figura 8 Possibilidade 1.

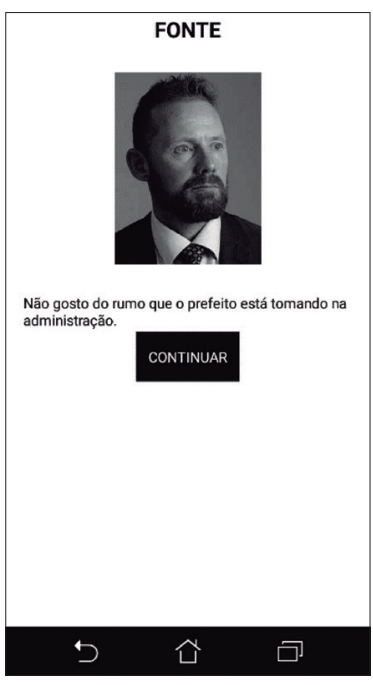

Figura 9 Possibilidade 2.

Imagens: Capturas de tela. Fotos: Licença CC Pixabay.

Essa lógica é seguida durante todo o jogo e cada decisão de escolha de perguntas resultará em novas perguntas, documentos ou possibilidades de entrevistas com outras fontes. É possível que em determinada escolha de pergunta o repórter não receba um documento ou informação importante relacionada à apuração da notícia. Também é possível que ele "desvie" de alguma fonte devido às escolhas feitas anteriormente. $\mathrm{O}$ jogador também deve tomar cuidado com os pedidos de "off the record" (quando a fonte pede para não ser identificada) por parte da fonte e caso ele entregue uma informação que deveria ficar guardada em "off" o mesmo terá uma penalidade que é recomeçar o jogo.

\subsection{Exercícios de redação}

Após a entrevista com todas as fontes, o jogador chegará a tela do exercício de aprendizagem. O guia (editor) vai instruir sobre o que deve ser feito. $\mathrm{O}$ jogador terá dicas sobre redação jornalísticas e poderá rever as informações coletadas.

Toda trilha narrativa da seção 2.6 é gravada num banco de dados Firebase. Dessa forma, ao tocar no botão "notas" (Figura 11) o repórter terá as informações que coletou durante o jogo e que são fruto das escolhas de perguntas que fez. Ou seja, o final e o texto redigido por um jogador não será igual ao de outro jo- 
gador tendo em vista que cada um terá as informações que optou por coletar durante o jogo. Essa prática é comum no dia a dia das redações onde as perguntas feitas aos entrevistados irão variar de entrevistador para entrevistador e gerar notícias com enfoques diferentes.

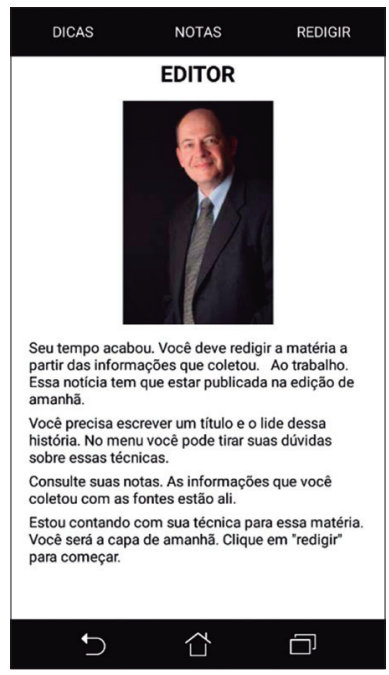

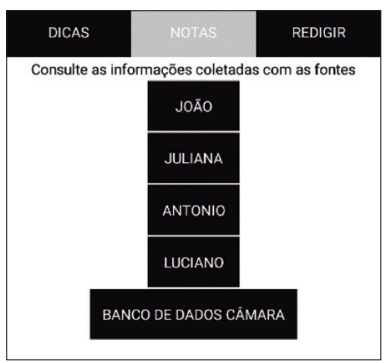

Figura 11 Notas do repórter.

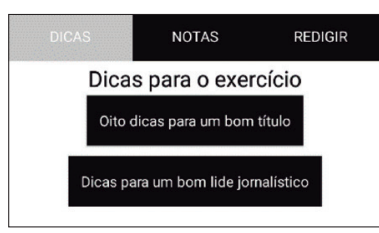

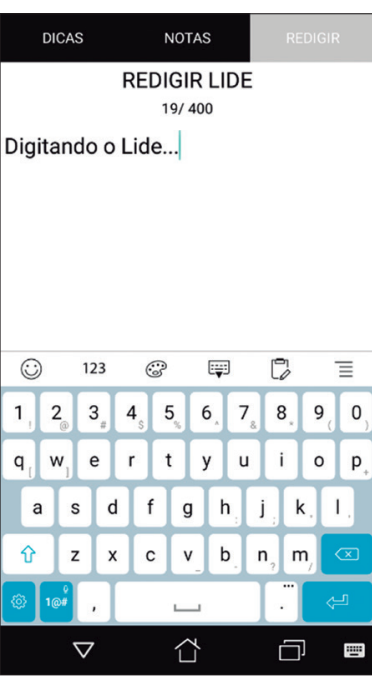

Figura 10 Instrução do exercício. Figura 12 Dicas de auxílio. Figura 13 Tela de redação. Imagens: Capturas de telas. Fotos: Licença CC Pixabay

\subsection{Armazenamentos dos dados}

Todos os dados da narrativa são armazenados num banco de dados em nuvem administrado pelo Firebase. No banco de dados são gravados os dados da trilha narrativa realizada pelo usuário e também as informações referentes ao exercício de aprendizagem. Ou seja, o título jornalístico e o lide redigidos por cada aluno ficam disponíveis para avaliação do professor e um retorno que no futuro pode ser automatizado.

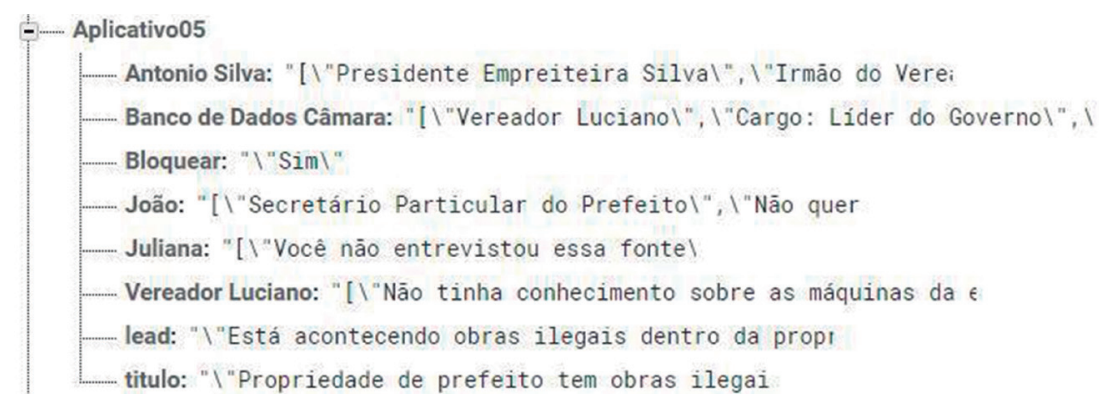

Figura 14 Dados do aplicativo no banco de dados Firebase.

Fonte: Google Firebase - Captura de tela. 


\section{AVALIAÇÃO DE USABILIDADE}

A avaliação do newsgame Aprendendo Jornalismo foi feita em dois momentos. O primeiro com alunos de jornalismo do primeiro e oitavo períodos da Universidade do Vale do Itajaí (Univali) e o segundo com alunos do segundo período da Universidade do Sul de Santa Catarina (Unisul). Em ambos se adotou a mesma metodologia de aplicação.

O primeiro passo foi fazer uma breve apresentação do jogo. Os usuários de dispositivos com sistema iOS deveriam participar da aplicação junto com outro aluno com dispositivo Android. Nessa versão do aplicativo não foi possível criar uma versão para sistemas iOS. Após essa explanação foi solicitada a assinatura do Termo de Consentimento Livre e Esclarecido (TCLE) e iniciou-se a aplicação do jogo com os alunos. Cada estudante utilizou o próprio dispositivo para a realização da tarefa. Finalmente, os alunos preencheram o Questionário de satisfação para a avaliação da usabilidade.

\section{INSTRUMENTOS PARA AVALIAÇÃO DE USABILIDADE}

Para a avaliação de usabilidade do newsgame Aprendendo Jornalismo utilizamos um questionário de satisfação baseado em uma proposta de avaliação de jogos educacionais elaborada por Savi, Wangenheim, Ulbricht \& Vanzin (2010). Esse modelo é uma junção da Avaliação de Treinamentos de Kirkpatrick, do Modelo ARCS, técnicas de User Experience em Jogos e a Taxonomia de Bloom.

Resumidamente:

Modelo de Kirkpatrick foi criado em 1994 por Donald Kirkpatrick e consiste em quatro níveis de avaliação de treinamentos com importâncias distintas e que ao avançar de um nível para o outro o aprendiz terá mais dificuldade na execução da tarefa. (Savi et al., 2010); Modelo ARCS é baseado na ideia da motivação para aprender. ARCS é um acrônimo para Atenção, Relevância, Confiança e Satisfação que são as bases desse modelo de avaliação (Savi et al., 2010); User Experience ou UX consiste em avaliar a experiência do usuário e divide-se em Imersão, Interação Social, Desafio, Diversão, Controle e Competência (Savi et al., 2010). Taxonomia de Bloom foi criada na década de 1950 sendo uma estrutura que pode ser aplicada para planejar, projetar e avaliar a efetividade da aprendizagem e treinamentos (Savi et al., 2010). Sendo assim o autor propõe a os seguintes fatores de usabilidade: Motivação, Experiência do Usuário e Conhecimento (Figura 15).

A partir do contexto dos fatores de usabilidade criou-se um questionário de satisfação utilizando uma Escala Likert de 5 pontos que pretende avaliar o nível de concordância do usuário. Esse questionário contou com 12 itens afirmativos 
onde o aluno deveria responder 1 para Discordo Totalmente, 2 para Discordo, 3 para não tem opinião, 4 para Concordo e 5 para Concordo Plenamente. O questionário ainda contou com três perguntas discursivas para coletar opiniões sobre as vantagens/desvantagens, benefícios/dificuldades e sugestões de melhoria para o newsgame Aprendendo Jornalismo.

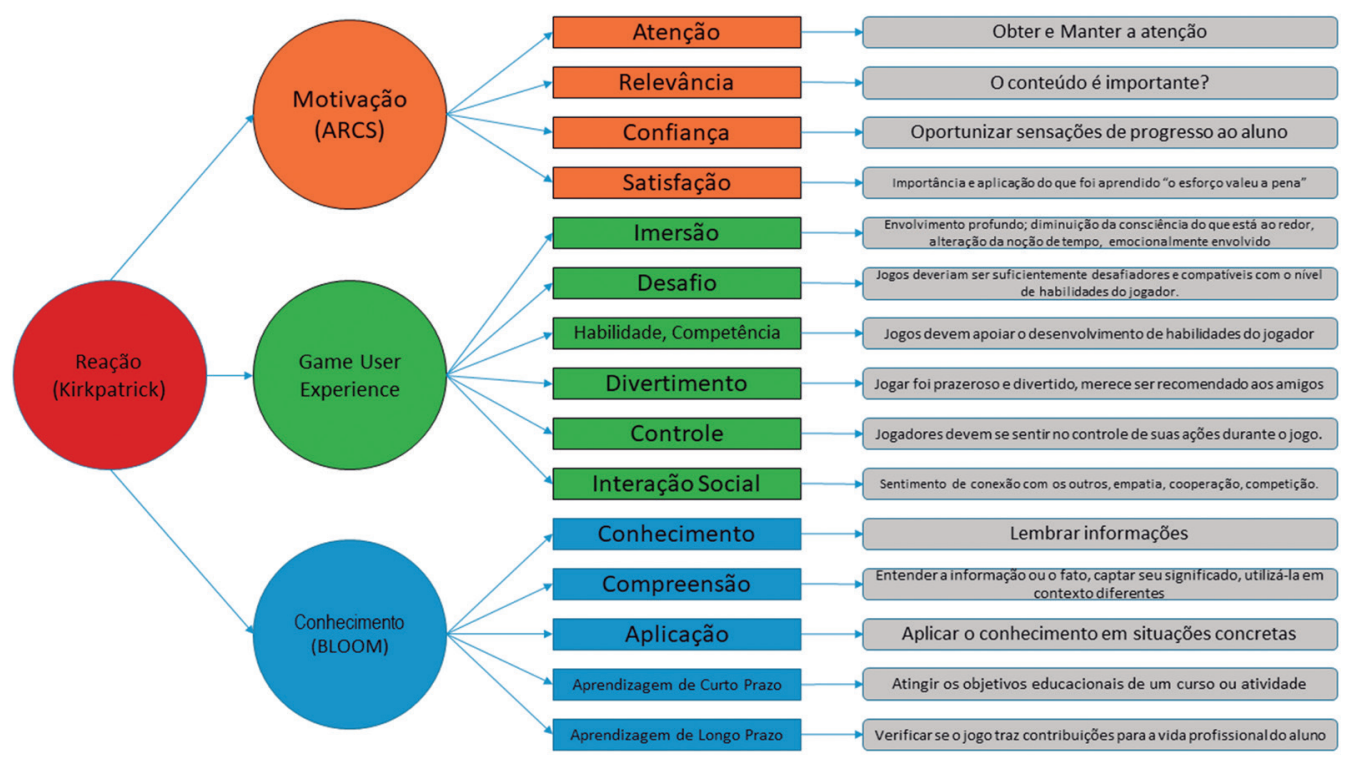

Figura 15 Modelo de avaliação de jogos educacionais.

Fonte: Elaborado pelos autores a partir de Savi et al. (2010).

Quadro 2 Perguntas do questionário de satisfação.

\begin{tabular}{|c|c|c|c|}
\hline & QUESTÃO & AVALIAÇÃO DE & CRITÉRIO \\
\hline 1 & A utilização do newsgame Jornalismo foi uma experiência satisfatória. & Motivação & Relevância \\
\hline 2 & $\begin{array}{l}\text { Durante a utilização do newsgame Jornalismo foi possível explorar os con- } \\
\text { ceitos relacionados com a prática da apuração de dados jornalística. }\end{array}$ & Conhecimento & \\
\hline 3 & $\begin{array}{l}\text { A narrativa do jogo contribui para o entendimento das relações de po- } \\
\text { der as quais o repórter está constantemente exposto. }\end{array}$ & Conhecimento & \\
\hline 4 & A interação com o newsgame Jornalismo é facilmente compreendida. & Motivação & Atenção \\
\hline 5 & $\begin{array}{l}\text { Não houve a necessidade de parar a atividade proposta diante do sur- } \\
\text { gimento de obstáculos na interação com a interface. }\end{array}$ & Motivação & Confiança \\
\hline 6 & $\begin{array}{l}\text { A narrativa utilizada facilitou na construção do título e lide proposto no } \\
\text { exercício final. }\end{array}$ & Motivação & Satisfação \\
\hline
\end{tabular}




\begin{tabular}{|c|l|l|l|}
\hline 7 & $\begin{array}{l}\text { As explicações e dicas oferecidas durante a experiência foram suficien- } \\
\text { tes para a finalização do exercício final }\end{array}$ & Experiência & Divertimento \\
\hline 8 & $\begin{array}{l}\text { Não encontrei erros relacionados ao newsgame Jornalismo durante a } \\
\text { realização da atividade desde o seu início até o fim }\end{array}$ & Motivação & Confiança \\
\hline 10 & $\begin{array}{l}\text { A utilização do newsgame Jornalismo auxiliou no meu aprendizado so- } \\
\text { bre redação jornalística }\end{array}$ & Experiência & Imersão \\
\hline 11 & $\begin{array}{l}\text { A utilização do newsgame Jornalismo reforça conteúdos éticos da prá- } \\
\text { tica jornalística }\end{array}$ & $\begin{array}{l}\text { Conhecimento é de fácil compreensão e me manteve motivado a } \\
\text { A utilização do newsgame contribui para o aprendizado sobre aplicação } \\
\text { do lide e do título jornalístico }\end{array}$ & Desafio \\
\hline
\end{tabular}

Fonte: Elaborado pelos autores.

\section{RESULTADOS}

A análise dos dados considerou a média de satisfação dentro da Escala Likert. O questionário estava dividido em cinco perguntas para a Motivação na escala ARCS, três perguntas para a Experiência do Usuário e quatro questões relacionadas ao Conhecimento de acordo com a Taxonomia de Bloom (Quadro 2). Portanto, a média para a Motivação foi de 3,34, Experiência 3,84 e Conhecimento 4,3 representados no Gráfico 1:

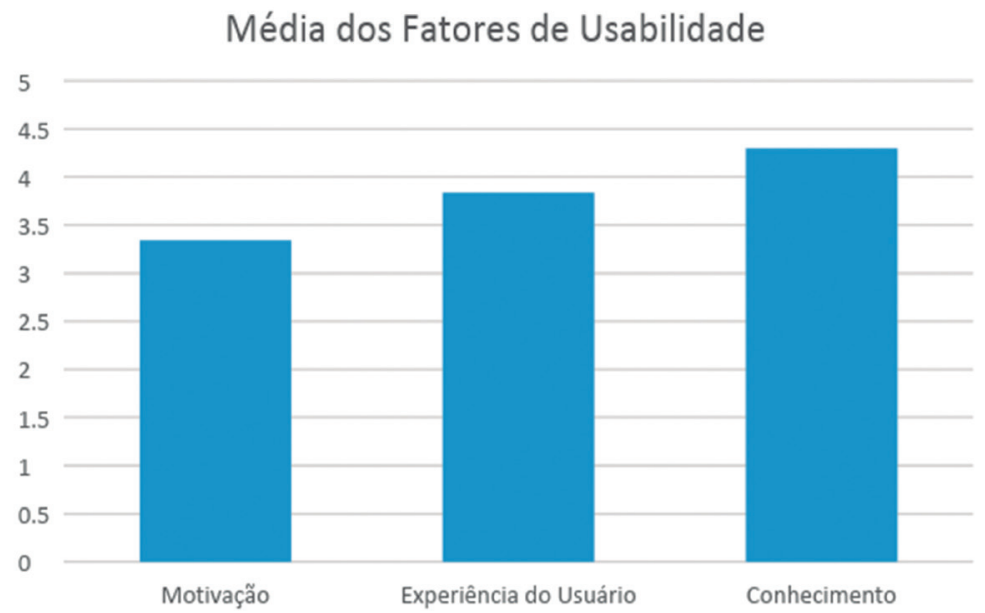

Gráfico 1 Média dos Fatores de Usabilidade.

Fonte: Elaborado pelos autores. 
A pergunta com a menor média foi a de número cinco (Quadro 2) relacionada com a avaliação de Motivação que obteve a média de 2,44. Certamente o resultado é devido há alguns problemas de usabilidade não críticos identificados na primeira versão do aplicativo móvel utilizado no estudo de caso. A questão com maior média foi a número dois relacionada à avaliação de Conhecimento que obteve a média 4,50. Essa última média corrobora a avaliação geral de Conhecimento que foi a maior do estudo.

Com relação às questões discursivas, relatamos a seguir a síntese das principais respostas:

Questão 1: Na sua opinião quais são os principais benefícios ou vantagens de se utilizar o newsgame Aprendendo Jornalismo para o estudo de Redação Jornalística?

Síntese: Observou-se que as vantagens mais comentadas têm relação com o formato gamificado de uma aplicação voltada para o ensino de redação jornalística. A maioria das respostas citou como benefício o aprendizado e treinamento que podem auxiliar no trabalho do professor.

Questão 2: Na sua opinião quais são as principais dificuldades ou desvantagens de se utilizar o newsgame Aprendendo Jornalismo para o estudo de Redação Jornalística?

Síntese: As principais respostas com relação às dificuldades estão relacionadas aos problemas de interação identificados pelos usuários. Com relação às desvantagens citou-se o layout pouco atrativo que deve ser melhorado e a possibilidade de se criar uma quantidade maior de perguntas que o repórter possa fazer para as fontes.

Questão 3: Quais são as suas sugestões de melhoria para o newsgame Jornalismo? Descreva, se houver, suas sugestões.

Síntese: Houve sugestões variadas, destacando que alguns alunos sugeriram um aplicativo com geolocalização onde o repórter pudesse caminhar pela cidade coletando e entrevistando fontes (ao estilo Pokemon Go). Também foi sugerida a criação de avatares para o repórter e que ao invés de fotografias as fontes fossem retratadas como "bonecos". A narrativa foi criticada e sugeriu-se uma melhoria na quantidade de fontes e que o usuário pudesse escolher tramas diferentes. No geral, a maioria considerável entendeu que é necessário executar melhorias no visual do newsgame Aprendendo Jornalismo e que em versões futuras deve-se melhorar aspectos de navegação que para alguns foi confusa e demorada de entender.

\section{CONCLUSÃO}

O ensino de Redação Jornalística se baseia tradicionalmente no aprendizado, pelo estudante, da técnica da Pirâmide Invertida que preza que as informa- 
ções devem estar sempre dispostas do mais para o menos importante em uma matéria jornalística. Para habilitar um profissional nessa prática é preciso que o mesmo domine a escrita do próprio idioma e também técnicas de entrevista, pauta e investigação. Sem contar, obviamente, a visão de mundo construída pelo indivíduo que lhe proporcionará enfoques diferentes sobre uma determinada história.

$\mathrm{Na}$ expectativa de auxiliar os professores no ensino da Redação Jornalísti$\mathrm{ca}$, os pesquisadores criaram um newsgame educativo baseado nas teorias da Narrativa Digital, do Aprendizado Baseado em Jogos Digitais e Geral dos Newsgames. Apesar dessa última não pensar diretamente na formação do jornalista e sim na persuasão do consumidor de notícias, a ideia é abrir um novo campo de influência de jogos de notícias para formação. Sendo assim, enquadrá-lo como newsgame é a possibilidade de transversar sobre um campo ainda pouco explorado do ensino do jornalismo que é a utilização de jogos educativos na formação profissional.

No estudo de caso realizado nos cursos de jornalismo da Univali e da Unisul pode-se confirmar que a proposta do newsgame Aprendendo Jornalismo teve boa aceitação enquanto sua abordagem educacional. $\mathrm{Na}$ avaliação do conhecimento gerado a média dada ao aplicativo pelos usuários foi de 4,30 numa escala Likert de 1 a 5. Entretanto, é necessário que o aplicativo evolua. Nesse primeiro teste alpha somente usuários de smarthphones com sistema Android puderam participar do teste. Assim sendo, criar versões para IOs e desktop são necessidades identificadas com os usuários.

Os usuários também sugeriram melhorias na interface, criação de avatares e a possibilidade de inserir geolocalização nas versões futuras do newsgame Aprendendo Jornalismo. Sendo assim, a conclusão é pela necessidade de reiniciar o projeto, conforme o Ciclo da Engenharia de Usabilidade proposta por Cybis, Betiol e Faust (2007, p. 104). Nessa primeira fase concluímos a avaliação de usabilidade, o projeto e os testes que indicam o caminho para uma nova rodada do ciclo. Para isso, será necessário que em versões futuras possamos utilizar um ambiente de desenvolvimento mais estável que nos permita criar um aplicativo com um mínimo de possíveis problemas de interação e que eleve a experiência do usuário acima dos 3,84 conseguidos com essa primeira versão. Assim, será possível estruturar um jogo educativo para o ensino de jornalismo que abranja diversas áreas deontológicas da prática jornalística.

\section{REFERÊNCIAS}

Becker, M. L. (2013). Contribuições para um novo programa de redação jornalística. Revista Brasileira de Ensino de Jornalismo, Brasília, v. 3, n. 12, p. 24-43. Semestral. 
Recuperado em 20 outubro, 2017, do <http://www.fnpj.org.br/rebej/ojs/index.php/rebej/ article/view/304/189>.

Bianco, N. R. del. (2004) A Internet como fator de mudança no jornalismo. Recuperado em 27 outubro, 2017, <http://www.bocc.ubi.pt/pag/bianco-nelia-internet-mudanca-jornalismo.pdf $>$.

Canavilhas, J. (2006). Webjornalismo: da pirâmide invertida à pirâmide deitada. Recuperado em 21 outubro, 2017,<http://www.bocc.ubi.pt/pag/canavilhas-joao-webjornalismo-piramide-invertida.pdf $>$.

Castells, M. (1999). A sociedade em rede. 6. ed. São Paulo: Paz e Terra. Tradução: Roneide Venancio Majer.

Cybis, W., Betiol, A. H. \& Faust, R. (2007). Ergonomia e usabilidade: conhecimentos, métodos e aplicações. São Paulo: Novatec.

Hal A. (2017). Instituto de Tecnologia de Massachusetts (Ed.). Qualquer um pode construir aplicativos que afetem o mundo. Recuperado em 25 outubro, 2017, <xplore/about-us.html>.

Madej, K.S. (2007). Characteristics of early narrative experience: connecting print and digital game. 2000. (Order No. NR41016) - Simon Fraser University (Canada), Ann Arbor, 2007.

Prensky, M. (2012). Aprendizagem baseada em jogos digitais. São Paulo: Senac São Paulo.

Rodrigues, D. C. (2009). Jornalismo 2.0. Toledo: Slideshare. 32 slides, color. Imagem do Slide 7. Recuperado em 25 outubro, 2017, <https://pt.slideshare.net/danirodrigues/jornalismo-20-2771877>.

Savi, R., Wangenheim, C. G. V., Ulbricht, V. \& Vanzin, T. (2010). Proposta de um modelo de avaliação de jogos educacionais. Novas tecnologias na educação, Porto Alegre, v. 8, n. 3, p. 1-10, Quadrimestral.

Seabra, G. A. \& Santos, L. A. (2014). NewsGames - teoria geral aplicada dos games baseados em notícias: criando as bases narrativas de um novo modelo de jornalismo online (Teorias dos News Games, Livro 2) (Locais do Kindle 109-114). NewsGames. Edição do Kindle.

Sicart, M. (2008). Newsgames: theory and design. In: 2008, Entertainment Computing - Icec. Entertainment Computing - ICEC 2008: $7^{\text {th }}$ International Conference. Pittsburgh: Springer Berlin Heidelberg. p. 27-33. (Lecture Notes in Computer Science, v. 5.309).

Sousa, J. P. (2008). Uma história breve do jornalismo no ocidente. Porto: Universidade Fernando Pessoa. 284 p. Recuperado em 15 setembro, 2017, <http://www.bocc.ubi.pt/ $\mathrm{pag} /$ sousa-jorge-pedro-uma-historia-breve-do-jornalismo-no-ocidente.pdf $>$.

Sousa, J. P. (2017). Jornalismo on-line. Forum media: Revista do Curso de Comunicação Social, Viseu, 2003. Trimestral. Recuperado em 25 outubro, 2017, <http://www.ipv. pt/ forumedia/5/13.htm>. 